\title{
POLÍTICA (E AÇÃO) PÚBLICA, TERRITÓRIO E O PAPEL DA GEOGRAFIA
}

\section{Public Policy (and Action), Territory, and the Role of Geography:}

Prof $f^{a}$ Neli Aparecida de Mello-Théry

Universidade de São Paulo, Escola de Artes, Ciências e Humanidades. Rua Arlindo Béttio, 1000 - Parque Ecológico do Tietê, CEP: 03828-000 - Sao Paulo, SP - Brasil Telefone: (11) 30911029 - namello@aol.com

\section{$a a a_{a a}$}

\begin{abstract}
Resumo
O eixo estruturante deste artigo será a analise das políticas territoriais no contexto da discussão sobre o papel e as contribuições da Geografia na política (e ação) pública e suas representações espaciais. Para tanto abordarei em dois itens a literatura científica internacional e as principais características teóricas dos geógrafos brasileiros, como foco da análise, relacionando-os aos seus universos político e institucional. Considerando que a concentração do conhecimento geográfico brasileiro em política pública enfoca políticas espaciais (territoriais, urbanas, agrárias e ambientais), procuro fundamentar-me na literatura clássica e contemporânea que trata de política pública (abreviada como PP) e do papel do Estado. É no segundo momento que se destacam as relações entre política (e ação) pública e o território, realçando-as enquanto campo disciplinar de reflexão e teorias.
\end{abstract}

Palavras-chave: Políticas públicas, Geografia, políticas territoriais

\begin{abstract}
The structural axis of this article is the analysis of territorial policies in the context of discussion about the role and contributions of geography in public policies (and actions) and its territorial representations. I will therefore discuss two items in the international scientific literature and the main theoretical characteristics of Brazilian geographers, as the focus of analysis, relating them to their political and institutional champs. Given that the concentration of geographical knowledge in Brazilian public policy focuses on territorial policies (territorial, urban, agricultural and environmental), I will re-visit classic and contemporary literature which deals with public policy (abbreviated as PP) and the role of the State. As a second step il will insist on the relationship between policies (and actions) and public territory, while highlighting the disciplinary field of thought and theories.
\end{abstract}

Key words: public policy, Geography, territorial politics.

\section{Résumé}

Cet article est fondé sur l'analyse des politiques territoriales dans le contexte du débat sur le rôle et les contributions de la géographie dans la politique (et l'action) concernant l'espace public et ses représentations. Je mettrai donc l'accent sur deux points de la littérature scientifique internationale et les principales caractéristiques théoriques des géographes brésiliens, en les rapportant à leurs univers politique et institutionnel. Étant donné que l'essentiel des connaissances géographiques en matière de politique publique brésilienne se concentre sur les politiques spatiales (territoriales, urbaines, agricoles et environnementales), je m'appuie sur la littérature classique et contemporaine qui traite des politiques publiques (en abrégé PP) et le rôle de l'État. Dans un deuxième temps j'insiste sur la relation entre la politique (et l'action) et le territoire public,en tant que champ disciplinaire de la pensée et les théories.

Mots-clé: polítiques publiques, Geographie, polítiques territoriales.

\section{$a_{a} \boldsymbol{a}_{a a}$}




\section{INTRODUÇÃO}

Na perspectiva clássica, política, originada da palavra grega pólis se referia às "coisas" da cidade (urbano, público, civil e social). Aristóteles (séc. 4 a.C.), porém, se referia à política como a ciência do Governo e à forma de governar a cidade. Já na era contemporânea, pólis se refere ao Estado.

A política diz respeito a um conjunto de atividades que faz referência ao Estado, como tal esta estreitamente vinculada ao poder, podendo ser entendida como "um conjunto de procedimentos/ marcos institucionais, pactos que expressam relações de poder e que se orienta à resolução de conflitos no que se refere a bens públicos". É, portanto, intencional e abrangente e terá sempre caráter estatal, ainda que sua execução possa envolver agentes privados, constituindo o que Frey (2000) considerou como polity.

Política pública é o processo pelo qual os diversos grupos tomam decisões coletivas, as quais se convertem em uma política comum (algo compartilhado), caracterizada pela palavra inglesa "politics". O conteúdo material destes processos é identificado como "policy".

Uma das características principais é que políticas públicas constituem-se de decisões e ações que estão revestidas da autoridade soberana do poder público. Estas dimensões acontecem simultânea e permanentemente, estão entrelaçadas, inter-relacionadas e são interdependentes, influenciando-se de forma mútua.

No âmbito da ciência geográfica, o conhecimento produzido a respeito das políticas públicas distingue o território como elemento norteador. Os geógrafos concentram-se majoritariamente no estudo daquelas que influenciam o espaço e que objetivam a sua própria gestão, seja nas ambientais, urbanas, rurais ou regionais. Roberto Lobato em Questões atuais da reorganização do território (1996) assegura que a gestão do território implica o controle da organização social, incluindo, em muitos casos, o controle de sua gênese e dos processos que a mantêm ou a alteram. A diferenciação de áreas, a gestão do processo de criação de valor, de circulação e apropriação da mais valia é o centro da gestão do território.

Após um período de decadência da importância das políticas públicas em função da visão de Estado mínimo, ocorre, no contexto atual um novo fortalecimento do papel das políticas públicas. Nas políticas ambientais, pela importância da definição de espaços protetores da biodiversidade; nas urbanas, pela demanda de reestruturação do espaço e o reordenamento do território em face à atual fragmentação das cidades; nas rurais, pelas repercussões dos processos urbanos no meio rural e nas regionais, em países onde ainda há necessidade da indução de processos de desenvolvimento para regiões menos favorecidas.

\section{O PAPEL DO ESTADO NAS POLÍTICAS PÚBLICAS}

O Estado moderno constitui-se em um conjunto de instituições públicas que envolvem múltiplas relações com o complexo social num território delimitado. O Estado detém o poder e a autoridade para fazer as políticas se tornarem válidas para toda a população.

Poulantzas em O Estado, o poder e o socialismo (1978) propõe uma teoria do Estado capitalista. Seu conceito de Estado capitalista tinha uma perspectiva relacional de poder, devendo o Estado ter a presença, em seus aparelhos, das classes dominantes e também das classes dominadas (inspirado em Foucault). O Estado estaria permeado pelas contradições e lutas sociais. Considerava que a política é a ação das lutas de classes e o Estado não é um ator, tendo como função ser o "fator de coesão" entre as classes.

Harvey (2004:91) ao analisar a lógica territorial considera que o Estado não é inocente, nem necessariamente passivo em relação a esses processos, uma vez que reconheça a importância de promover e capturar a dinâmica regional como fonte de seu próprio poder, ele pode procurar influenciar a dinâmica por meio de suas políticas e ações. 
O Estado moderno, para Boisier (1996), em Modernidad y Territorio, tem que ter uma estrutura territorial sistêmica e tem que fazer a condução tanto territorial quanto política. Ele considera as múltiplas interseções entre território e objetivos nacionais, reforçando que não se pode abandonar o ordenamento do território aos efeitos territoriais da lógica econômica. Reconhece o Estado territorial não apenas na construção jurídica-política abstrata, mas, na prática, com a própria a gestão regional, que, em função das megatendências descentralizadoras da globalização que colocam o território organizado (em qualquer escala, sobressaindo-se a escala regional) em um lugar de protagonista na nova ordem internacional. Há uma interdependência entre objetivos nacionais e território. O território organizado assume o papel de suporte da competitividade para o qual a gestão pública é central.

No final do século XX, o questionamento das ideias sobre o Estado-mínimo tem provocado uma nova revalorização do Estado como ator na promoção de políticas públicas e no exercício do planejamento, agora com ênfase na participação da sociedade civil organizada, contradizendo a visão poulantiziana.

No início do século XXI, Massardier em Politiques et actions publiques (2003) considera que o Estado é um dos atores do processo de ação política, embora proponha incluir o processo de mobilização social e as forças de mercado. Para ele, a análise de políticas públicas demanda a introdução da análise multiescalar e de outros elementos como os processos coletivos, a responsabilidade pelas externalidades, a (in)governabilidade das sociedades ocidentais.

\section{DESENVOLVIMENTO DO TEMA}

\section{Relações entre Política (e ação) Pública e território}

Os fundamentos desta relação são políticos. Em sua obra Geografia Política, Sánchez (1992) argumenta que as atuações políticas têm reflexos espaciais-territoriais e que os conflitos são inerentes ao processo A cada escala em que se considerem as relações sociais ocorrerão conflitos espaciais, pois a política representa o jogo de interesses sociais contrapostos. Os primeiros reflexos são representados pela dinâmica social, pois são significativos a apropriação, os processos de controle e a política como gestão. A política implica no estabelecimento de estratégia e táticas frente aos outros membros da sociedade para impor critérios e formas de atuação.

Definir estratégias e organizar táticas requer articular a gestão do poder. Poder definido por Sánchez (1992) como a capacidade de intervir sobre o espaço e modificá-lo, aspecto pelo qual se distinguirão as politicas territoriais. O que ocorre em um território não é exclusivamente resultado das decisões, atuações e processos que ocorrem em seu interior (intrapoder), mas estas são afetadas, em maior ou menor grau, por decisões e atuações exteriores (interpoder) ao território considerado.

Primeiro, a apropriação racional do espaço-território pelas ações que definem o homem como ser histórico: transformação do espaço natural, mediante um processo de apropriação e domínio sistemático das leis da natureza. A apropriação é uma condição necessária para poder localizar, assentar e funcionalizar o espaço-território. Ou seja, implica no reconhecimento social de seu uso por um agente.

Segundo, o controle do espaço-território que assume importância como espaço econômico e requer a existência de uma organização social coerente entre instancias politica, econômica e ideológico-cultural.

Terceiro, a gestão do espaço e a intervenção territorial. Toda atuação política (econômica, ideológica, cultural, militar) tem sempre uma componente espacial-territorial. A gestão política começa por dotar-se de uma organização territorial. Se espera que seja eficiente para alcançar os objetivos que o poder persegue, começando como uma forma de divisão ou de hierarquização territorial ad hoc.

Quarto, a politica territorial que se configura por um conjunto de propostas estratégicas, de médio a longo prazo, assim como pelas correspondentes formulações de atuação dirigida para in- 
terferir sobre o território, a fim que assuma as formas resultantes como adequadas ao conjunto de interesses que controlam o poder político. Fator tempo é inseparável de toda política.

Sánchez (1992) entende a politica territorial como um processo consciente de manipulação do território e uma não politica territorial, como um processo de efeitos espaciais indiretos que se derivam de ações políticas que não tinham considerado o espaço como variável de atuação.

\section{Políticas públicas espaciais, enquanto um campo disciplinar de reflexão e teorias.}

Importante destacar que enquanto campo disciplinar de reflexão e construção de teorias, no meio científico e no meio da gestão pública, as políticas públicas espaciais voltam a ter relevância para a ciência geográfica, no final dos anos 1980, quando do processo de redemocratização brasileiro. Embora tenha havido um envolvimento prático da Geografia no planejamento governamental desde os anos 1940, após o período militar houve um processo de rejeição da temática pelos geógrafos decorrente da necessidade de se livrar do estigma da Geografia dos militares, levantado por Lacoste em sua polêmica "A Geografia, isso serve, em primeiro lugar, para fazer a guerra" (1976).

Considerando-se a formação doutoral em Geografia e o registro de suas linhas de pesquisa em políticas públicas nos programas de pós-graduação em Geografia identificaram-se os principais pesquisadores na plataforma Lattes $(\mathrm{CNPq})$. O gráfico ressalta os geógrafos estão envolvidos com esta temática (49).

Os principais pesquisadores estão em universidades públicas, estaduais ou federais. Sobressaem-se a Estadual Paulista (UNESP - Presidente Prudente e Rio Claro), a de São Paulo (USP); as federais de Brasília (UnB), Santa Catarina (UFSC). Piauí (UFPI), Bahia (UFBA), do Rio de Janeiro (UFRJ). Na região Nordeste destacam-se as pesquisas em políticas públicas agrárias e políticas ambientais; na região Sul, política territorial e de fronteira e política territorial ligada ao estudo de redes ou ainda as políticas territoriais, políticas ambientais e políticas urbanas-ambientais. No Distrito Federal, na UnB destaca a linha de Políticas Públicas Espaciais e Ambientais.

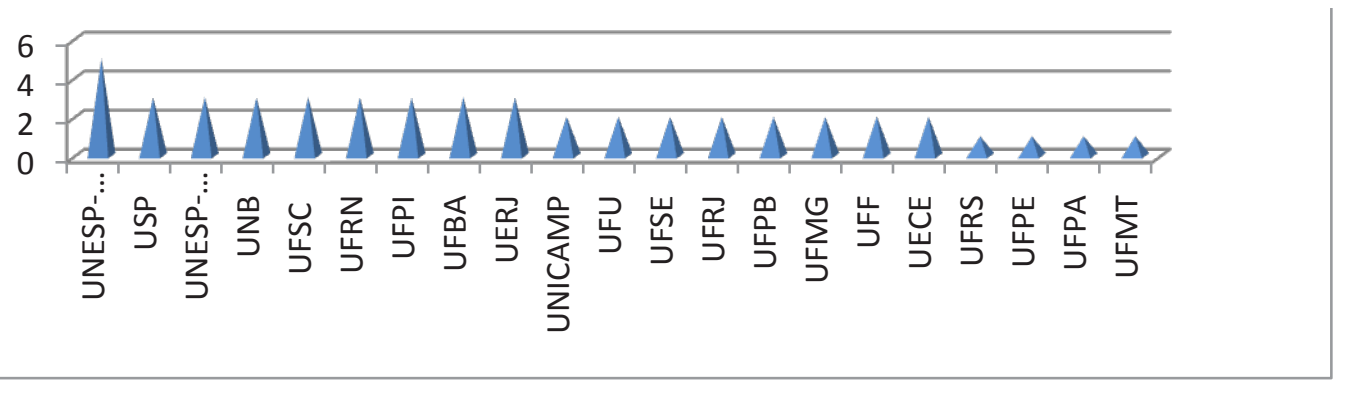

Figura 1 - Pesquisadores em PP programas de pós-graduação em Geografia.

Os estudos das políticas territoriais, urbanas, rurais, regionais e ambientais são os mais proeminentes. No entanto, ocorreram três temáticas pouco expressivas para o conjunto das contribuições geográficas, mas que apontam outras preocupações dos pesquisadores: a política de saúde, a de educação e as paisagens, legados e significados dos grandes eventos esportivos.

Entendemos que o pensamento teórico da Geografia nas políticas públicas concentra-se em uma grande linha teórica, crítica, de base marxista e/ou estruturalista. Apesar disso, é possível identificar abordagens diferentes, nas quais, enfatiza-se um ou outro aspecto mais determinante.

A abordagem das políticas públicas está constantemente relacionada aos problemas de desenvolvimento. A ênfase dada atualmente à noção de desenvolvimento não pode prescindir da incorporação da dimensão ambiental e suas condicionantes. Muitos compromissos globais têm sido acordados por meio de convenções e protocolos, os quais se refletem nas políticas nacionais, obrigando, também, aos cientistas inseri-los na análise da importância e de suas repercussões nas múltiplas escalas territoriais. 
Tomemos como exemplo o que Diniz e Crocco (2006) argumentam a respeito do aumento da "racionalidade sistêmica" nas políticas públicas de desenvolvimento regional e urbano que se inserem no discurso da sustentabilidade quando objetivam o melhor uso dos recursos dos programas existentes.

Em minha visão as concepções presentes no pensamento onusiano provocam repercussões sobre a organização territorial brasileira e irão também influenciar com novas teorias do desenvolvimento as configurações do espaço e o ordenamento e servir de referencial para as contribuições geográficas no âmbito das políticas públicas.

a) Geógrafos críticos (estruturalistas, marxistas) apregoam a luta contra as desigualdades sociais, indicam caminhos para o desenvolvimento, baseado nas condicionantes locais, endógenas e muitos deles acabaram por adotar a defesa da proteção do meio ambiente. Muitos dentre eles entendem que esse desenvolvimento supõe uma cooperação internacional, a consideração do meio ambiente, propõe uma nova ordem social, justa e equitativa e um processo de escolha democrática. "Os pilares do desenvolvimento alternativos são por um lado, a busca da harmonia com a natureza, ou seja, a harmonização dos objetivos sociais, ecológicos e econômicos e por outro lado uma abertura consequente no sentido da promoção de mudanças institucionais. Traduzir esses conceitos em práticas implicava, sem dúvida, entrar num terreno onde somos todos aprendizes", tanto na experimentação quanto na reflexão teórica.

O novo corpus teórico contempla, na Geografia, a analise das relações Norte-Sul; valorizam o debate econômico, social e ecológico, privilegia a segurança alimentar e energética. Para a Geografia significa também uma retomada da preocupação com a natureza e suas relações políticas e sociais.

Há uma divisão quanto à percepção do Estado: ou ele é visto como estrategista e planejador do novo modelo ou como mediador entre os interesses de apropriação dos recursos naturais e as estratégias das empresas transnacionais e os direitos das comunidades. Alguns entendem que as rupturas e conflitos são parte do espaço político e entendem que para pensar em política pública é fundamental compreender a multidimensionalidade do território e a presença do conflito, sobretudo no âmbito das esferas de poder representativas como os conselhos, onde os atores estão lá presentes, na defesa de seus interesses.

b) geógrafos que trabalham na ótica da gestão (ambiental, territorial, urbana, rural ou regional) e do desenvolvimento do território: o debate territorial muitas vezes se circunscreve à distribuição de competências entre níveis de governo, seu poder e a distribuição de recursos entre regiões. Alguns autores abordam o potencial intrínseco de desenvolvimento que o território possui (Becker, 1996; Costa, 1998) ou que trazem uma visão integradora dos espaços, atores, agentes, mercados. O que se pode definir como abordagem territorial do desenvolvimento: integração e coordenação entre atividades, recursos e atores, avaliação do financiamento das infra-estruturas, da presença dos conselhos municipais de desenvolvimento (Abramovay, 2001, 2002). O território é visto apenas como espaço de governança, destacando a participação e a diversidade da sociedade.

Nesta abordagem predominam as tratativas de zoneamento e ordenamento do território, da análise e elaboração dos planos diretores municipais, dos estudos dirigidos aos planos de manejo e gestão territorial de unidades de conservação. Inserem-se também a avaliação de programas governamentais e suas repercussões sobre o espaço.

A seguir o quadro-síntese das linhas de pesquisa atuais dos pesquisadores cadastrados na plataforma Lattes do CNPQ demonstra as temáticas de interesse dos geógrafos brasileiros: 
Quadro 1 - Linhas de pesquisas atuais dos pesquisadores cadastrados na plataforma Lattes do CNPQ

\begin{tabular}{|c|c|c|}
\hline Instituição & № de & Linhas de pesquisas atuais do pesquisador ou área de atuação \\
\hline UERJ & 3 & $\begin{array}{c}\text { A gestão do urbano: espaço público e sociabilidades. } \\
\checkmark \quad \text { A produção do espaço turístico. } \\
\checkmark \quad \text { Paisagens, legados e significados dos grandes eventos esportivos } \\
\checkmark \quad \text { Globalização, Políticas Públicas e Reestruturação Territorial }\end{array}$ \\
\hline UFU & 2 & 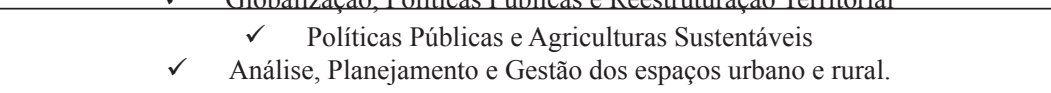 \\
\hline UFPE & 1 & $\begin{array}{ccc} & \checkmark \quad \text { Políticas Públicas e Gestão Local } \\
\checkmark \quad \text { Políticas Urbanas e práticas territoriais das políticas sociais. }\end{array}$ \\
\hline UECE/UFS & 2 & \begin{tabular}{ccc}
$\checkmark$ & \multicolumn{2}{c}{ Estrutura e Dinâmica Populacionais } \\
& Trabalho, Renda e Desigualdades Sociais \\
& $\checkmark$ & Urbanização e Regionalização \\
& $\checkmark$ & Sociodemografia do Semi-árido \\
& $\checkmark$ & Política Urbana
\end{tabular} \\
\hline UFSC & 3 & $\begin{array}{c}\checkmark \quad \text { Redes, Organização Territorial e Politicas Públicas, principalmente politica territorial } \\
\checkmark \quad \text { Redes, Organização Territorial e Políticas Públicas } \\
\checkmark \quad \text { Políticas de Planejamento Urbano - Cidade e Sociedade } \\
\checkmark \quad \text { Políticas Educacionais }\end{array}$ \\
\hline UFF & 2 & $\begin{array}{ll}\checkmark & \text { Metrópole, Politicas Publicas, Identidade e Movimentos Sociais } \\
\checkmark & \text { Políticas públicas em unidades de conservação no estado do RJ } \\
\end{array}$ \\
\hline UFPA & 1 & $\checkmark \quad$ Turismo e Políticas Públicas na Amazônia \\
\hline UFBA & 3 & $\begin{array}{c}\checkmark \text { A Geografia dos Assentamentos na Área Rural } \\
\checkmark \quad \text { Organização espacial e Estudos regionais } \\
\checkmark \quad \text { Análise urbano-regional } \\
\end{array}$ \\
\hline UNESP (Rio Claro) & 3 & 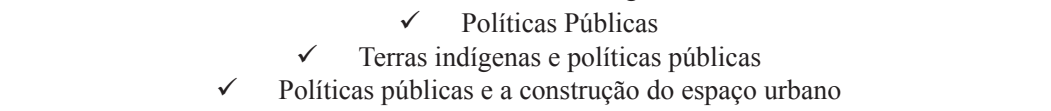 \\
\hline $\begin{array}{l}\text { UNESP (Presidente } \\
\text { Prudente) }\end{array}$ & 5 & $\begin{array}{cccc} & & \checkmark & \text { Políticas públicas e complexo agroindustrial } \\
\checkmark & \text { Políticas públicas, dinâmica regional e desenvolvimento territorial } \\
\checkmark & \text { Os efeitos sócio-espaciais dos sistemas agroindustriais } \\
& \checkmark & \text { Desenvolvimento territorial: impactos socioterritoriais } \\
& \checkmark & \text { Políticas públicas e exclusão social } \\
& \checkmark & \text { Desenvolvimento Rural } \\
& \checkmark & \text { Agricultura Familiar e economia agrária } \\
& \checkmark & \text { Políticas de Saúde } \\
\end{array}$ \\
\hline UNICAMP & 2 & $\begin{array}{ccc} & \checkmark & \text { Políticas Públicas } \\
\checkmark & \checkmark \quad \text { Dinâmica Territorial e Qualidade Ambiental } \\
\checkmark & \text { Dinâmica Territorial, Sistemas Técnicos Atuais e Novas Práticas Socioespaciais - Meio } \\
\text { ambiente urbano, Território e Novas Práticas Sócio-espaciais } \\
\checkmark & \text { Federalismo e território (os pactos territoriais que fundam o poder político do Estado) } \\
\checkmark & \text { Uso, Organização e Alienação do Território Brasileiro } \\
\checkmark & \text { Fronteiras internas, fragmentação e alienação do território: a criação de novos } \\
& \text { municípios e estados no Brasil } \\
\checkmark \quad \text { A ação de agentes hegemônicos no território brasileiro }\end{array}$ \\
\hline $\begin{array}{c}\text { UFMG - UFV- PIK } \\
\text { (Alemanha) }\end{array}$ & 1 & $\checkmark \quad$ Mecanismo do desenvolvimento limpo e políticas ambientais nacionais e internacionais \\
\hline (Alemanina) & 3 & 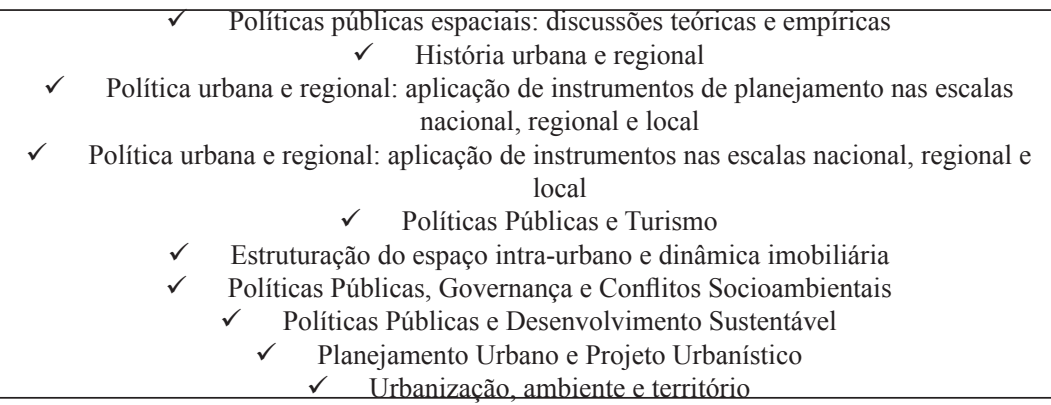 \\
\hline UFRN & 3 & $\begin{array}{ccc} & \checkmark & \text { Políticas públicas e dinâmica regional } \\
\checkmark & \text { Políticas Públicas, Desenvolvimento Rural e Ruralidade } \\
& \checkmark \quad \text { Políticas Públicas (turismo) } \\
& \checkmark \quad \text { Produção do espaço urbano e agrário } \\
\checkmark & \text { Políticas públicas de turismo e urbanização turística } \\
\checkmark & \text { Competitividade, turismo e diferenciação espacial } \\
\checkmark & \text { Competitividade turística de destinos potiguares. } \\
& \checkmark & \text { Políticas públicas, espaço e turismo }\end{array}$ \\
\hline
\end{tabular}




\begin{tabular}{|c|c|c|}
\hline UFPB/UFRN & 1 & $\begin{array}{ccc} & \checkmark & \text { Políticas Públicas } \\
& \text { Estudos Socioespaciais e Representações Cartográficas } \\
\checkmark & \text { Estudos urbanos e regionais } \\
\checkmark & \text { Geografia agrária e desenvolvimento sustentável } \\
& \checkmark \quad \text { Território, cultura e poder local }\end{array}$ \\
\hline UFPB & 1 & $\begin{array}{cc}\checkmark & \text { Políticas públicas e gestão de recursos hídricos no Nordeste } \\
\checkmark & \text { Gestão territorial dos recursos hídricos no Nordeste brasileiro } \\
\checkmark & \text { SERTÃO: Territorialidades e Representacões } \\
\end{array}$ \\
\hline UFPI & 3 & \begin{tabular}{ccc}
$\checkmark$ & \multicolumn{2}{c}{ Cidade, Solidariedade e Práticas Urbanas } \\
$\checkmark$ & Geografia, Política e Território \\
$\checkmark$ & Cidade e Políticas Urbanas \\
$\checkmark$ & Região, Desenvolvimento e Políticas Públicas \\
$\checkmark$ & Políticas públicas no espaço rural \\
$\checkmark$ & Urbanização, política e cidadania
\end{tabular} \\
\hline UFSE & 2 & $\begin{array}{cc}\checkmark & \text { Estado, Políticas Públicas, Território } \\
\checkmark & \text { Política Externa e Regionalismo } \\
\checkmark & \text { Planejamento e Políticas Urbanas } \\
\checkmark & \text { Desenvolvimento Local e Regional } \\
\checkmark & \text { Politica Macro e Dinâmica Mundial }\end{array}$ \\
\hline UFMT & 1 & $\begin{array}{c}\checkmark \checkmark \quad \text { Mudanças Climáticas e Políticas Públicas } \\
\checkmark \quad \text { Impactos sócio-ambientais da expansão da soja na Pré-Amazônia Mato-grossense }\end{array}$ \\
\hline USP & 3 & 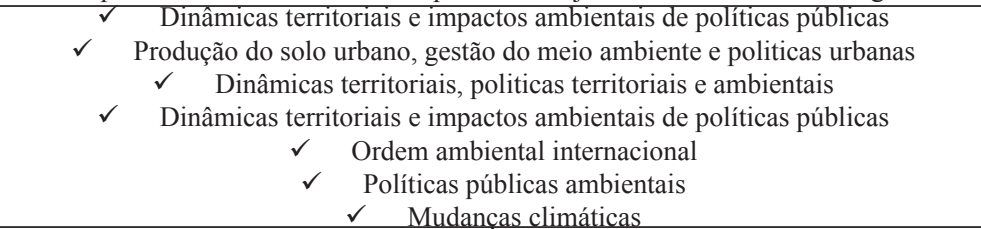 \\
\hline UFRGS & 1 & $\begin{array}{c}\checkmark \quad \text { Estado, Políticas Públicas e Desenvolvimento Rural } \\
\checkmark \quad \text { Análise Territorial } \\
\end{array}$ \\
\hline UFRJ & 2 & $\begin{array}{ccc} & \checkmark & \text { Imaginário político e território } \\
\checkmark & \text { Regionalismo. Natureza e política } \\
\checkmark & \text { Desenvolvimento, ambiente e território } \\
& \checkmark \quad \text { Geopolítica da Amazônia }\end{array}$ \\
\hline
\end{tabular}

Fonte: Plataforma Lattes, CNPq, 2011. Organizado por Jodival Costa.

\section{CONSIDERAÇÕES FINAIS}

As contribuições geográficas para a problemática atual das políticas públicas apontam primeiramente para o reconhecimento de que a política pública promove transformações no território, para, em seguida explicitar uma crítica incisiva ao Estado enquanto representante de segmentos poderosos, de interesses escusos. Um Estado que não se preocupa com suas populações mais vulneráveis e que suas ações beneficiam, sempre, o poder econômico e político.

Além das críticas, outras abordagens apontam para a exigência da presença de Estado, seja na regulação das ações privadas, individuais, na determinação de bem público e coletivo e suas repercussões sobre o território. Apontam para a gestão do espaço e a intervenção territorial, indicando que as dinâmicas territoriais representam as configurações das ações econômicas, sociais e políticas sobre o espaço e o uso deste espaço deve ser objeto da ação do Estado, promovendo um (re) ordenamento do território. No entanto, este novo ordenamento há que ser diferente, que defina o uso dos territórios em alguns lugares, a favor do meio ambiente, a favor das populações indígenas, camponesas, quilombolas e não apenas a favor da expansão das atividades econômicas predominantes como, por exemplo, o agronegócio.

O resultado dessa exploração analítica foi a percepção de que novos campos teóricos foram (re)construídos no interior da ciência geográfica. A Geografia tem contribuições a dar construindo um novo campo do saber de maneira a envolver outros segmentos científicos, pois no mundo contemporâneo é impossível o isolamento disciplinar. Mais do que nunca, seus teóricos importam em introduzir e garantir a visão interdisciplinar, o diálogo, a discussão de alguns conceitos-chave. A Geografia tem contribuído com o resgate e a precisão de conceitos fundamentais como, por exemplo, a questão do poder, do território, dos atores e do Estado. 
Finalmente, penso que a inter-relação da gestão territorial como resultado das políticas públicas múltiplas (Estado, sociedade, instituições intergovernamentais e multilaterais) depende, sobretudo, de abordagem interdisciplinar. Depende também de críticas que permitam estimular a mudança do status quo: da desigualdade de uso do espaço ao acesso a todos. Estas críticas contribuirão de maneira construtiva para a presença do conhecimento geográfico como apoio ao avanço das próprias politicas públicas.

\section{REFERÊNCIAS BIBLIOGRÁFICAS}

ABRAMOVAY, Ricardo. Desenvolvimento territorial e capital social. In: SABOURIN, Eric; TEIXEIRA, Olívio. (Orgs.). Planejamento e desenvolvimento dos territórios rurais: conceitos, controvérsias e experiências. Petrolina: Embrapa, 2001, p. 87-101.

ALLIĖS, Paul. L'invention du territoire. Grenoble: Presses Universitaires de Grenoble, 1980.

BECKER, Bertha et al. (Orgs.). Geografia e meio-ambiente no Brasil. São Paulo : HUCITEC, 1995.

BECKER, Bertha. Informação e Território. Ciência Hoje, Rio de Janeiro, v. 20, p. 6-7, 1996.

BOISIER, Sergio. Modernidad y Territorio. Cuadernos del Ilpes, Instituto Latinoamericano y del Caribe de planificación económica y social. Santiago de Chile, 1996.

BRUNET, Roger. Le développement des territoires. Le Molin du Chateau: Éditions de l'Aube. 2004.

BRUNET, Roger. Le déchiffrement du monde, théorie et pratique de la géographie.Paris. Éditions Belin, 2001.

CASTRO, Iná; COSTA GOMES, Paulo Cesar; CORRÊA, Roberto Lobato (orgs). Brasil: questões atuais da reorganização do território. Rio de Janeiro: Bertrand Brasil. 1996.

18 CASTRO, Iná; MIRANDA, Mariana, EGLER, Claudio. Redescobrindo o Brasil, 500 anos depois. Rio de Janeiro, Bertrand Brasil, 1997.

CEPAL. Las nuevas funciones urbanas: gestión para la ciudad sostenible, División de Medio Ambiente y Asentamientos Humanos, Santiago, Chile. 2000.

COSTA, Wanderley Messias. O Estado e as políticas territoriais no Brasil. São Paulo: Ed. Contexto, 1988. COSTA, Wanderley Messias. Política e Território: os desafios da representação no contexto da democracia institucional. In: BECKER, B.. (Org.). Geografia Política e os Desafios do Desenvolvimento Sustentável. Rio de Janeiro: Berdrand - Brasil, 1998, p. 35-56.

COSTA, Wanderley Messias. Geografia Política e Geopolítica: discursos sobre o território e o poder ( $2^{\mathrm{a}}$ edição revisada). São Paulo: EDUSP, 2008.

DINIZ, Clélio Campolina e CROCCO, Marco (orgs.). Economia regional e urbana: contribuições teóricas recentes. Belo Horizonte: Editora UFMG, 2006.

FREY, Klaus. Políticas Públicas: um debate conceitual e reflexões referentes à pratica da análise de políticas públicas no Brasil. Planejamento e Políticas Públicas, IPEA: nº 21, jun/2000.

GORZ, André; BOSQUET, Michel. Écologie et politique. Paris: Seuil, 1978.

HAESBAERT, Rogério. Des-caminhos e perspectivas do território. In: Território e desenvolvimento: diferentes abordagens. 2004. p.87-120.

HAESBAERT, Rogério. Territórios Alternativos. Niterói: Contexto, 2002.

HARVEY, David. O novo imperialismo. São Paulo: Ed. Loyola, 2004.

MANÇANO, Bernardo. Sobre a tipologia de territórios. In: SAQUET, Marcos Aurélio; SPOSITO, Eliseu Saverio (Orgs.). Territórios e territorialidades: teorias, processos e conflitos. São Paulo: Expressão popular: UNESP. Programa de pós-graduação em Geografia, 2009. pp. 197-216.

MASSADIER, Gilles. Politiques et actions publiques. Paris: Armand Colin, 2003.

MELLO, Neli Ap. de. Políticas territoriais na Amazônia. São Paulo: Annablume, 2006.

MELLO-THÉRY, Neli Ap. de. Território e Gestão Ambiental na Amazônia. Terras públicas e os dilemas do Estado. São Paulo: Annablume, 2011. 
MORAES, Antônio Carlos Robert. Meio ambiente e ciências humanas. São Paulo : HUCITEC, 1994, segunda edição 2005 .

POULANTZAS, Nicos. Estado, o poder e o socialismo (1978). Tradução Rita Lima. Rio de Janeiro: Edições Graal, 1981.

RAFFESTIN, Claude. Por uma Geografia do Poder. São Paulo, Ática, $1^{\text {a }}$ edição, 1993.

RIBAS, Alexandre Domingues; SPOSITO, Eliseu Saverio, SAQUET, Marcos Aurélio. Território e desenvolvimento: diferentes abordagens. Francisco Beltrão: Uni oeste, 2004

SACHS, Ignacy e VIEIRA, Paulo Freira (orgs). Rumo à ecossocioeconomia. Teoria e prática do desenvolvimento. São Paulo: Cortez, 2007.

SACHS, Ignacy. A terceira margem: em busca do ecodesenvolvimento. São Paulo : Cia das Letras, 2009.

SACHS, Ignacy. Stratégie de l'éco-développement. Paris: Eds. Ouvrières, 1978.

SACHS, Ignacy. Pour une économie politique du développement. Paris: Flammarion, 1977.

SÁNCHEZ, Joan-Eugeni. Geografía Política. Madrid: Editorial Síntesis. S.A. 1992.

SAQUET, Marcos Aurélio. Por uma abordagem territorial. In: SAQUET, Marcos Aurélio; SPOSITO, Eliseu Savério (Orgs.). Territórios e territorialidades: teorias, processos e conflitos. São Paulo: Expressão popular: UNESP. Programa de pós-graduação em Geografia, 2009, p.73-94.

SOUZA, Celina. Políticas públicas: uma revisão da literatura. Sociologias, Ano 8, v. 3, nº 16, 2006. http:// www.scielo.br/scielo.php?script=sci_arttext\&pid=S1517-45222006000200003\&lng=pt\&nrm=iso. Consultado em 14 agosto 2006.

SOUZA, Marcelo Lopes. "Território" da divergência (e da confusão): em torno das imprecisas fronteiras de um conceito fundamental. in SAQUET, Marcos Aurélio, SPOSITO, Eliseu Savério (Orgs.). Territórios e territorialidades: teorias, processos e conflitos. São Paulo: Expressão popular: UNESP. Programa de pós-graduação em Geografia, 2009. pp. 57-73.

Trabalho enviado em agosto de 2011 Trabalho aceito em outubro de 2011 